\title{
RETRACTED ARTICLE: Human recombinant $\alpha$-crystallins: temperature dependence of diffusion coefficients
}

\author{
Yannis Georgalis • Nathalie Braun • \\ Jirka Peschek • Marie-Sousai Appavou
}

Received: 10 August 2012/Revised: 26 November 2012/Accepted: 11 December 2012/Published online: 11 January 2013

(C) European Biophysical Societies' Association 2013

The Authors in agreement with the Editor-in-Chief of the "European Biophysics Journal", the European Biophysical Societies' Association, and the publisher hereby retract the article entitled "Human recombinant $\alpha$-crystallins: temperature dependence of diffusion coefficients" by Georgalis Y, Braun N, Peschek J, Appavou MS; published online in the "European Biophysics Journal" on January 11, 2013. This article is retracted due to unsolved legal reasons.

Y. Georgalis

Department of Chemistry, Technische Universität München,

Lichtenbergstrasse 4, 85747 Garching, Germany

N. Braun · J. Peschek

Center for Integrated Protein Science, Technische Universität

München, Lichtenbergstrasse 4, 85747 Garching, Germany

M.-S. Appavou ( $\square)$

Jülich Center for Neutron Science at FRMII,

Lichtenbergstrasse 1, 85747 Garching, Germany

e-mail: m.s.appavou@fz-juelich.de

URL: http://iffwww.iff.kfa-juelich.de/var/Mitarbeiter/

e_jcns_frm_staff.html 